\title{
Special Issue "Advanced Techniques and Efficiency Assessment of Mechanical Processing"-Editorial Note and Critical Review of the Problems
}

\author{
Daniel Saramak (1D)
}

check for

updates

Citation: Saramak, D. Special Issue "Advanced Techniques and Efficiency Assessment of Mechanical

Processing"-Editorial Note and Critical Review of the Problems. Minerals 2021, 11, 1428. https:// doi.org/10.3390/min11121428

Received: 3 December 2021

Accepted: 16 December 2021

Published: 17 December 202

Publisher's Note: MDPI stays neutral with regard to jurisdictional claims in published maps and institutional affiliations.

Copyright: (C) 2021 by the author Licensee MDPI, Basel, Switzerland. This article is an open access article distributed under the terms and conditions of the Creative Commons Attribution (CC BY) license (https:// creativecommons.org/licenses/by/ $4.0 /)$.
Department of Environmental Engineering, Faculty of Civil Engineering and Resource Management, AGH University of Science and Technology, Mickiewicza 30 Av., 30-059 Cracow, Poland; dsaramak@agh.edu.pl

\section{Introduction}

The value chain of metal production consists of a number of processing steps that result in obtaining the final metal product from the given raw material. Each stage, from mining through to mineral processing and metallurgical treatment, is equally crucial and indispensable and performs a specific role in the entire mining and processing system. Mechanical processing is a step within the mineral processing stage. Its main duty is to provide material of a sufficient size, and thus generate an acceptable level of useful mineral liberation. This allows the required results to be achieved in downstream beneficiation operations, which are measured through the recovery of useful metals and the level of pay metal loss in tails. The primary technological operations associated with mechanical processing are comminution and classification. The aim of mechanical processing is, therefore, to provide a sufficient size reduction in material by dividing it into particles or fragments, which are measured using the comminution ratio level. All of these operations aim to remove impurities and other unwanted fractions from the feed, which is then mainly applied to the aggregate production sector. However, these operations are often treated as supplementary, since their incorporation into the technological circuit mostly depends on the qualitative characteristics and the contained impurities of the feed, which consists mostly of clayish and dusty fine fractions.

The mechanical processing stage is a relatively simple step and numerous investigations found in the literature recognised its technological solutions. However, despite its apparent simplicity, multistage crushing and grinding operations, including its separation and classification, make this processing stage more complicated than initially realised. The problem lies in the huge potential of its steering and control arrangement, as well as the variety of changeable operational parameters in the circuit. In light of this, three major groups of operational variables can be distinguished:

- Operational parameters of crushing and classifying devices;

- Physical and mechanical characteristics of the feed material;

- Technological regime and the manner of carrying out a specific operation.

The efficient operation of mechanical processing in technological circuits can be analysed from several points of view:

- Achieving the required technological outputs measured through the obtained size reduction in the feed material and specific particle size composition;

- Economical assessment of the real and potential effects through the analysis of the relationship between costs and benefits;

- Environmental and social aspects resulting from a general negative impact of mining on the environment and society;

- Application of optimization approaches and methods, together with simulation models based on theories of mathematical and statistical modelling;

- $\quad$ Other approaches not listed above or a combination of several scopes. 


\section{Methodology and Results}

The assessment of the impact of a specific topic can be evaluated on the basis of a number of scientific publications concerning the issue. Bibliometric analysis is a good example of this approach, and by using this tool it is possible to perform qualitative and quantitative analyses of scientific publications registered in databases to obtain interesting results. In general, there are a relatively high number of publications concerning raw material treatment at the stage of mechanical treatment/processing but, to verify this, a detailed analysis must be performed, based on the records registered in the Web of Science (WoS) database. In the WoS Core Collection, the all fields option for searched documents was chosen, and the analysed period was All years (1900-2021). The search was performed on 24 November 2021. The obtained search results (732,139 records) were then refined using the research area Mining and mineral processing in Web of Science Categories. As a result, 4285 records were obtained. The obtained records were analysed according to the year of publication, region/country, source of publication (journal name), research area, scientific institution, and the keywords. An analysis according to the keywords was performed separately for author words and for editor words. The CiteSpace application was used as a tool for obtaining the data and visualization. The number of publications registered in WoS database across individual years is presented in Figure 1.

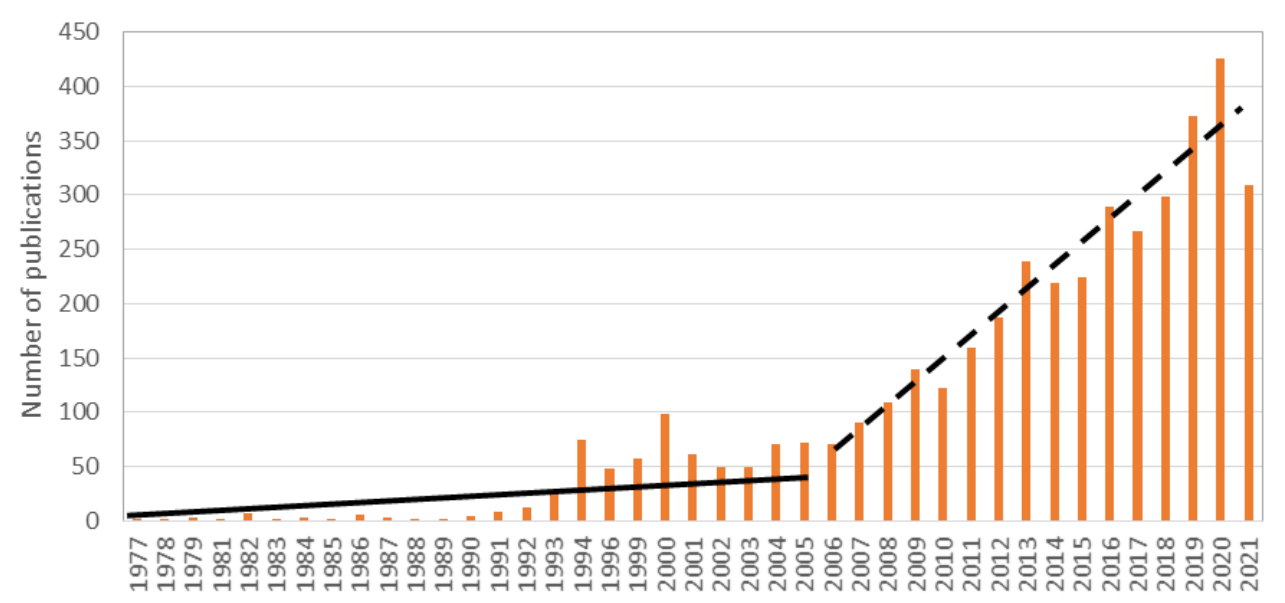

Figure 1. Number of publications issued yearly that concern mechanical processing of raw materials for the period 1977-2021.

As shown, two primary periods can be distinguished in a general trend:

- In the period between 1977 and 2005, the increase in the number of publications in consecutive years is very low; therefore, the trend can be determined as a constant (solid line in Figure 1);

- $\quad$ Since the year 2006, a regular increase in publication numbers can be observed for each consecutive calendar year. This trend can be approximated using a linear function (dashed line in Figure 1).

The above results demonstrate that problems concerning the mechanical processing of raw material generated significant interest, especially in the last decade. Next, an analysis of publications regarding regions and countries is presented. The number of publications according to specific countries are presented in Table 1, where the top 10 countriers with the most publications are shown. The results show that nearly $30 \%$ of the world's publications regarding mechanical processing technology of raw materials originate from China. The USA is the second country with the most publications, totalling around $17 \%$, with 741 papers. Australia is the next country, with its share of publications exceeding 7\%, closely followed by Germany and Russia, who produced 254 and 237 publications, respectively. 
Table 1. Top 10 countries with the highest number of publications in Web of Science database.

\begin{tabular}{ccc}
\hline Country & Number of Publications & Percentage Share \\
\hline China & 1226 & 28.638 \\
USA & 741 & 17.309 \\
Australia & 313 & 7.311 \\
Germany & 254 & 5.933 \\
Russia & 237 & 5.536 \\
Canada & 203 & 4.742 \\
Poland & 200 & 4.672 \\
India & 164 & 3.831 \\
Iran & 156 & 3.644 \\
England & 113 & 2.640 \\
\hline
\end{tabular}

Publications grouped according to research areas are presented in Table 2. All records are within the main research area, i.e., Mining and mineral processing, but most publications have more than one assigned research area. The three most popular areas with more than one thousand publications are Metallurgy, Metallurgical Engineering, Mineralogy and Materials Science Multidisciplinary. It is worth mentioning that a single record (publication) can be assigned to several areas; therefore, the cumulative percentage share in Table 2 is higher than $100 \%$. This is clearly visible based on the three mentioned categories. The reason for this is that the cumulative percentage share for them only exceeds 100 percent; many publications concerning the problems of mechanical processing must be associated with at least two of the top three areas.

Table 2. Most frequent research areas associated with the publications concerning the issue.

\begin{tabular}{ccc}
\hline Research Area & Number of Publications & Percentage Share \\
\hline Metallurgy Metallurgical & 1739 & 40.583 \\
Engineering & 1631 & 38.063 \\
Mineralogy & 1567 & 36.569 \\
Materials Science & 575 & 13.419 \\
Multidisciplinary & 534 & 12.462 \\
Engineering Geological & 220 & 5.134 \\
Engineering Chemical & 203 & 4.737 \\
Geosciences Multidisciplinary & 75 & 1.750 \\
Geochemistry Geophysics & 65 & 1.517 \\
Energy Fuels & 63 & 1.470 \\
Chemistry Physical & & \\
Environmental Sciences &
\end{tabular}

An analysis of obtained records from the WoS database, grouped according to journals, is presented in Table 3, including the top 20 journals with the highest number of publications related to mechanical processing. The top journal on this list, JOM, has an almost $20 \%$ share of the number of published articles, and a significant gap can be observed between the first and second position on the list.

An analysis of the impact factor value shows that the number of publications in a specific journal is, to some extent, correlated with IF. However, this link is not very strong and is influenced by several factors, mostly by the assignation of individual titles to different disciplines and categories. If there is an asterisk at the value of an individual IF, it denotes that this value is older than the year 2020. Table 3 also presents the positions of a specific journal determined by the number of quartiles in the Mining and mineral processing category. From this, two conclusions can be drawn. First, detailed profiles of journals differ and second, not all the journals are equally interested in problems concerning the mechanical aspects of mineral processing. In turn, the number of publications according to individual scientific institutions is presented in Table 4 . The results show that among the five topmost publishing institutions, three are located in China, with almost a $12 \%$ share. 
Table 3. Top 20 journals with the highest number of publications concerning mechanical processing. *: the value of an individual IF; -: this value is older than the year 2020.

\begin{tabular}{|c|c|c|c|c|}
\hline Title of Journal & $\begin{array}{l}\text { Number of } \\
\text { Publications }\end{array}$ & $\begin{array}{c}\text { Percentage } \\
\text { Share }\end{array}$ & IF & Quartile \\
\hline JOM & 798 & 18.641 & 2.474 & 2 \\
\hline $\begin{array}{l}\text { International Journal of Rock } \\
\text { Mechanics and Mining Sciences }\end{array}$ & 398 & 9.297 & 7.135 & 1 \\
\hline $\begin{array}{l}\text { International Journal of Minerals } \\
\text { Metallurgy and Materials }\end{array}$ & 319 & 7.452 & 2.232 & 3 \\
\hline Minerals Engineering & 289 & 6.751 & 4.765 & 1 \\
\hline $\begin{array}{c}\text { International Journal of Mineral } \\
\text { Processing }\end{array}$ & 229 & 5.349 & $2.688 *$ & - \\
\hline Minerals & 133 & 3.107 & 2.644 & 2 \\
\hline $\begin{array}{c}\text { JOM Journal of The Minerals Metals } \\
\text { Materials Society }\end{array}$ & 115 & 2.686 & - & - \\
\hline $\begin{array}{c}\text { Journal of University of Science and } \\
\text { Technology Beijing }\end{array}$ & 106 & 2.476 & $0.919 *$ & - \\
\hline $\begin{array}{l}\text { International Journal of Mining } \\
\text { Science and Technology }\end{array}$ & 76 & 1.775 & 4.084 & 1 \\
\hline Archives of Mining Sciences & 64 & 1.495 & 1.127 & 4 \\
\hline $\begin{array}{c}\text { Physicochemical Problems of Mineral } \\
\text { Processing }\end{array}$ & 64 & 1.495 & 1.213 & 4 \\
\hline Advanced Materials Research & 60 & 1.402 & - & - \\
\hline Journal of Mining Institute & 57 & 1.331 & - & - \\
\hline Minerals Metals Materials Series & 55 & 1.285 & - & - \\
\hline Mining of Mineral Deposits & 55 & 1.285 & - & - \\
\hline Acta Geodynamica et Geomaterialia & 49 & 1.145 & 1.176 & 4 \\
\hline Acta Montanistica Slovaca & 48 & 1.121 & 1.413 & 3 \\
\hline $\begin{array}{c}\text { Journal of The South. African Institute } \\
\text { of Mining and Metallurgy }\end{array}$ & 48 & 1.121 & 0.807 & 4 \\
\hline Journal of Mining Science & 44 & 1.028 & 0.456 & 4 \\
\hline $\begin{array}{c}\text { Mineral Processing and Extractive } \\
\text { Metallurgy Review }\end{array}$ & 44 & 1.028 & 5.283 & 1 \\
\hline
\end{tabular}

Table 4. Top 10 publishing institutes.

\begin{tabular}{ccc}
\hline Research Area & Number of Publications & Percentage Share \\
\hline $\begin{array}{c}\text { University of Science } \\
\text { Technology Beijing }\end{array}$ & 228 & 5.326 \\
$\begin{array}{c}\text { China University of Mining } \\
\text { Technology }\end{array}$ & 184 & 4.298 \\
United States Department of & 129 & 3.013 \\
$\quad$ Energy Doe & 94 & 2.196 \\
Russian Academy of Sciences & 93 & 2.172 \\
Chinese Academy of Sciences & 88 & 2.056 \\
Northeastern University & 79 & 1.845 \\
$\quad$ China & 69 & 1.612 \\
Central South University & 68 & 1.588 \\
University of Queensland & 60 & 1.402 \\
Helmholtz Association & & \\
AGH University of Science & & \\
Technology & &
\end{tabular}

\section{Qualitative Analysis of the Content and Discussion}

The analysis below concerns the quality of content in articles connected with the mechanical processing of raw materials. The analysis was performed both on the basis of keywords included in the articles that were connected with mechanical processing and indexed in the WoS database, and through a content review of the papers published within 
this Special Issue. Two types of keywords were analysed: author keywords, and editorial keywords, i.e., phrases added by the editorial boards of the journal.

\subsection{Keywords Analysis}

An analysis of author keywords indicated that the top ten most used keywords constituted almost one-third of records (Table 5). It can also be seen that a majority of these keywords were associated with environmental aspects.

Table 5. Top 10 author and editor keywords, common phrases in bold font.

\begin{tabular}{cccccc}
\hline Author Keywords & $\begin{array}{c}\text { Percentage } \\
\text { Share }\end{array}$ & $\begin{array}{c}\text { Number } \\
\text { of Cases }\end{array}$ & Editor Keywords & $\begin{array}{c}\text { Percentage } \\
\text { Share }\end{array}$ & $\begin{array}{c}\text { Number } \\
\text { of Cases }\end{array}$ \\
\hline $\begin{array}{c}\text { air pollution } \\
\text { particulate matter }\end{array}$ & 11.67 & 3088 & particulate matter & 2.93 & 3336 \\
air quality & 10.01 & 2648 & pm10 & 2.91 & 3312 \\
$\begin{array}{c}\text { source } \\
\text { apportionment }\end{array}$ & 1.75 & 993 & air pollution & 2.66 & 3036 \\
$\begin{array}{c}\text { air pollutant } \\
\text { indoor air quality }\end{array}$ & 1.41 & 394 & pm2.5 & 2.44 & 2780 \\
heavy metal & 1.22 & 373 & pollution & 2.03 & 2316 \\
nitrogen dioxide & 0.98 & 258 & particle & 1.87 & 2129 \\
$\begin{array}{c}\text { chemical } \\
\text { composition }\end{array}$ & 0.70 & 184 & exposure & 1.82 & 2069 \\
size distribution & 0.70 & 184 & aerosol & 1.61 & 1837 \\
\hline
\end{tabular}

Two phrases are predominant regarding the number of cases; their share exceeds $20 \%$, and both of them are connected with environmental problems. However, this only confirms a global trend observed in the mineral processing sector, which aims to pay more attention to environmental aspects. Phrases strictly typical to mineral processing are also on the top 10 list, but they are located at the end of the list. An analysis of editor keywords indicated the likelihood that, in the case of the author keywords, the share of individual phrases was more equally distributed, and it was not possible to clearly distinguish a single predominant word. However, similar to the author keywords, editor keywords were mostly related to environmental problems, only confirming that the greatest concern of the raw material sector is its impact on the environment. More detailed visualizations are shown in Figures 2 and 3.

\subsection{Content Analysis}

An analysis of SI content suggested that the dominating topic was technology. A detailed analysis of the content shows that the majority of papers concern various methods of classification and separation: from screening classification [1,2] and sorting [3], to jig [4] and flotational [5] beneficiation, with one publication related to crushing [6]. Authors applied various methods to monitor the obtained qualitative characteristics $[1,3]$ and utilized simulation and modelling tools $[2,5,7]$ in order to evaluate the operation effectiveness of individual separation techniques. Technological aspects were also underlined in a review of recent directions of comminution technology development [8]. It is accepted that the mechanical processing stage predetermines the efficiency of downstream separation operations, especially in the technological circuits of ore beneficiation. For industries associated with the processing of rock materials, mechanical processing, in turn, directly influences the characteristics of final products in terms of size and shape [9]. This was the subject of investigations in papers by Saramak, and Gawenda et al. [4,8]. 


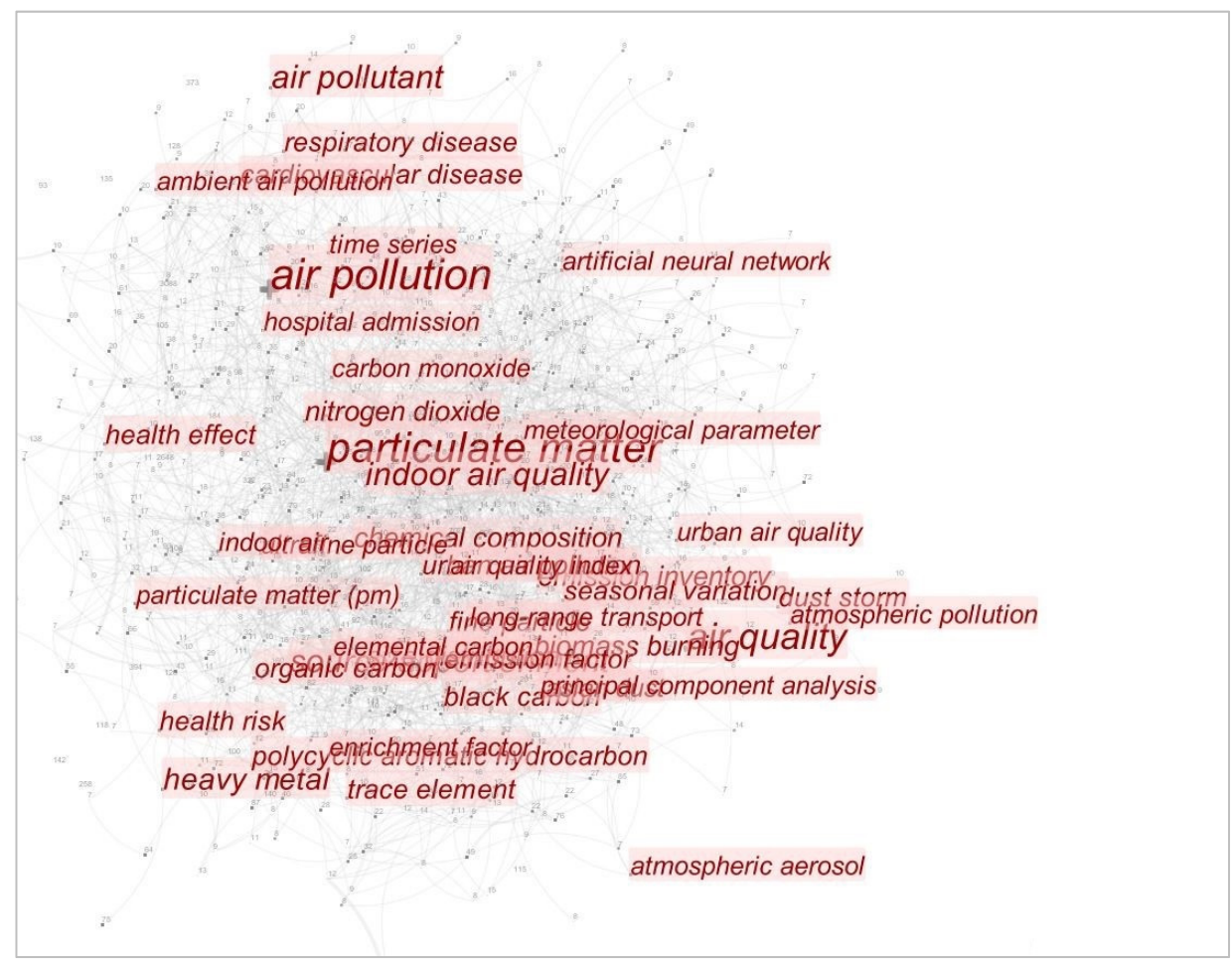

Figure 2. Visualization of author keywords.

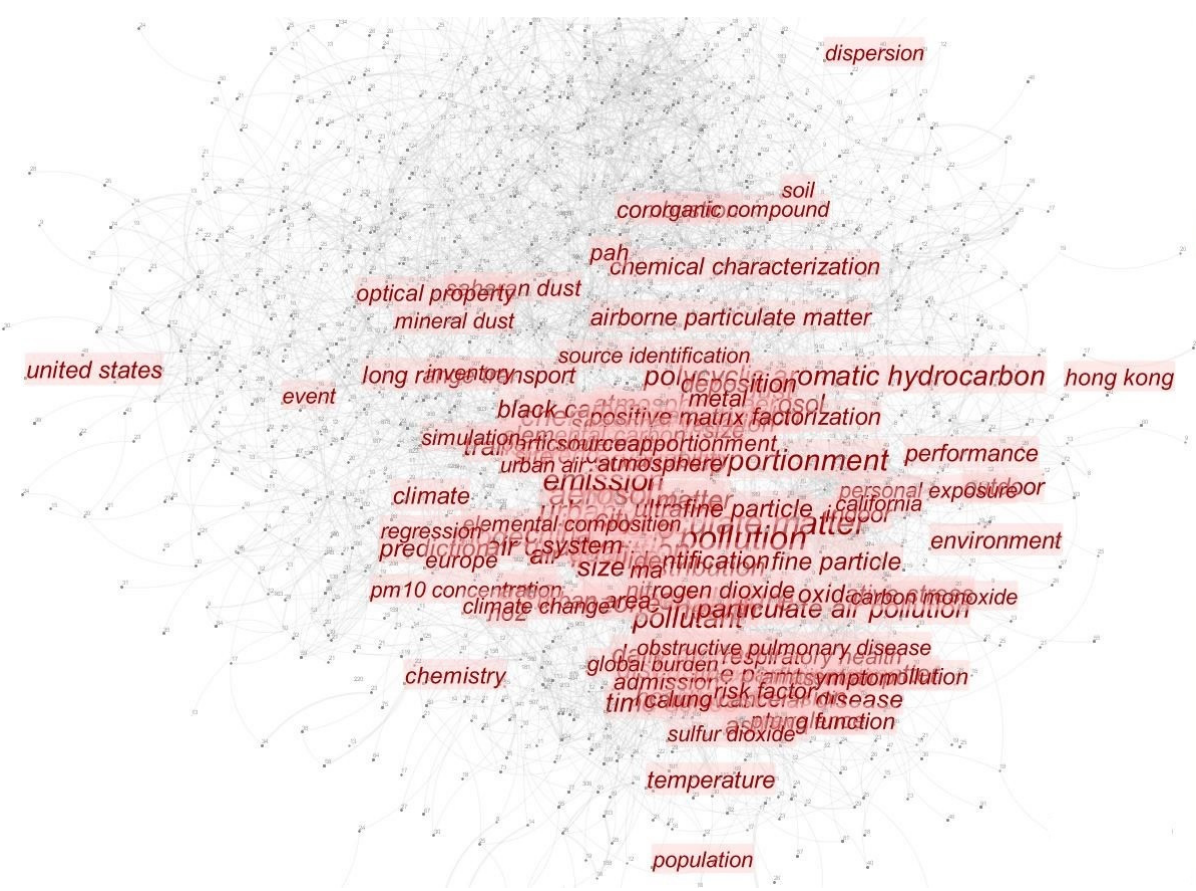

Figure 3. Visualization of editor keywords.

Screening technology was the scope in works of N. Duda-Mróz et. al. And C. Yu et. al. [1,2]. In the work [1] focuses on development of diagnostic procedures and monitoring of screening device, particularly its spring, to estimate the time needed for the safe operation of the device and early damage detection. One approach consisted of an analysis of vibration data registered for the specific components of the device, i.e., springs and bearings, and identification of disturbances by means of calculated techniques of wavelet filtering. The second paper, concerning size classification [2], focuses on the screening of high-viscosity, fine, cohesive particles. The authors analysed the achieved screening efficiency from the 
scope of the device operation (different sections of the mat surface) and surface energy of particles. The authors also utilized the DEM modelling technique to simulate the behaviour of material on the screen. They also concluded that the service energy level of the particles regarding adhesion was inversely proportional to the screening efficiency. The study of [3] concerns the sorting technology and investigates the system of Dual-Energy X-ray (DE-XRT) and its ability to distinguish sulphides from non-sulphides. For this type of material, it was possible to achieve a very high accuracy and the system appeared to be an effective sensor that could be used to differentiate sulphides from waste material. The issues presented in this work have an advantage over recent achievements in the development of visual methods and the increasing sensitivity and accuracy of detecting tools [10]. These methods are significant from the scope of the proper characterization of granular material, especially in its description according to particle size, but also for other features, such as the density, porosity, or content of different types of materials. These issues can be found in paper [7], where problems concerning granular material segmentation during transportation are analysed. The practical aspects of this work seem to be significant due to the possibility of online monitoring and the early detection of improper or undesired states. The application of neural networks algorithms makes the system more effective. This is especially significant from the scope of material characterization and helps to select and optimize the downstream separation techniques of granular material. Similar aspects were included in the work of [1]. Optimizational models were also developed in the work of Niedoba et al. [5], which applied copper ore flotation. A mathematical model based on taxonomic methodology was developed, as well as the adopted functions enabling the determination of the optimal technological parameters of flotation, depending on the material characteristics and process regime. This approach is in line with the popular direction of modelling in mineral processing; assuming the binding of parameters in theoretical models or functions with a material, device, and process course $[2,8,9,11]$.

Rock materials enrichment is also present in studies concerning the beneficiation of aggregates in a jig device [4]. This problem is common for a wide group of rock materials, confirming the opinion expressed in other papers of this Special Issue: that the proper characterization of granular material is of key significance in the effective separation of rock materials. The utilization of a patented system of material classification, upstream to the beneficiation, significantly improves separation according to size and shape, but the selection of operational parameters for this system is possible due to the knowledge on the size and shape characteristics of the processed material.

One paper is strictly related to comminution [7], concerning the problem of material breakage in dynamic conditions. Due to the complexity of this process, resulting from a series of interactions occurring both in space and time, this problem is under constant investigation. This paper's findings are interesting as they concern the general problem of raw materials breakage, namely the low effective utilization of energy for breakage and high energy-consumption. The results can contribute to a better understanding of selected mechanisms relating to dynamic breakage, such as the probabilities of establishing the given size of particles and their location within the crushed product.

\section{Conclusions}

Papers included in this Special Issue of Minerals, entitled "Advanced Techniques and Efficiency Assessment of Mechanical Processing" addressed significant problems related to the processing of raw materials that can be grouped into the following categories:

- Methods and techniques of monitoring and the visual characterization of granular materials;

- Modelling and optimization of process effectiveness, using advanced computational tools and algorithms;

- Efficiency assessment of selected operations that are crucial in the mineral processing industry, and can be performed from a technological or economic point of view.

Several aspects of this Special Issue were found to be related to environmental problems, especially in papers concerning the treatment of rock materials. An analysis of 
keywords in articles registered in the WoS database indicated that issues concerning the environment are of key significance. Its role in scientific research is therefore becoming increasingly important.

Acknowledgments: The Guest Editor thanks all authors of articles included in this Special Issue, as well as reviewers, Assistant Editors and the Editorial Board for their input and work towards this Special Issue. Special thanks also due to the Bibliometric Analysis Group from the Main Library of AGH University of Science and Technology for support and valuable comments on the bibliometric data analysis.

Conflicts of Interest: The author declare no conflict of interest.

\section{References}

1. Duda-Mróz, N.; Anufriiev, S.; Stefaniak, P. Application of Wavelet Filtering to Vibrational Signals from the Mining Screen for Spring Condition Monitoring. Minerals 2021, 11, 1076. [CrossRef]

2. Yu, C.; Geng, R.; Wang, X. A Numerical Study of Separation Performance of Vibrating Flip-Flow Screens for Cohesive Particles. Minerals 2021, 11, 631. [CrossRef]

3. Zhang, Y.; Yoon, N.; Holuszko, M.E. Assessment of Sortability Using a Dual-Energy X-ray Transmission System for Studied Sulphide Ore. Minerals 2021, 11, 490. [CrossRef]

4. Gawenda, T.; Saramak, D.; Stempkowska, A.; Naziemiec, Z. Assessment of Selected Characteristics of Enrichment Products for Regular and Irregular Aggregates Beneficiation in Pulsating Jig. Minerals 2021, 11, 777. [CrossRef]

5. Niedoba, T.; Pięta, P.; Surowiak, A.; Şahbaz, O. Multidimensional Optimization of the Copper Flotation in a Jameson Cell by Means of Taxonomic Methods. Minerals 2021, 11, 385. [CrossRef]

6. Guo, Q.; Pan, Y.; Zhou, Q.; Zhang, C.; Bi, Y. Kinetic Energy Calculation in Granite Particles Comminution Considering Movement Characteristics and Spatial Distribution. Minerals 2021, 11, 217. [CrossRef]

7. Ma, X.; Zhang, P.; Man, X.; Ou, L. A New Belt Ore Image Segmentation Method Based on the Convolutional Neural Network and the Image-Processing Technology. Minerals 2020, 10, 1115. [CrossRef]

8. Saramak, D. Challenges in Raw Material Treatment at the Mechanical Processing Stage. Minerals 2021, 11, 940. [CrossRef]

9. Ambróst, W. Jigging: A review of fundamentals and future directions. Minerals 2020, 10, 998. [CrossRef]

10. Gawenda, T.; Krawczykowski, D.; Krawczykowska, A.; Saramak, A.; Nad, A. Application of Dynamic Analysis Methods into Assessment of Geometric Properties of Chalcedonite Aggregates Obtained by Means of Gravitational Upgrading Operations. Minerals 2020, 10, 180. [CrossRef]

11. Barrios, G.K.P.; Tavares, L.M. A preliminary model of high pressure roll grinding using the discrete element method and multi-body dynamics coupling. Int. Journ. Min. Proc. 2016, 156, 32-42. [CrossRef] 